\title{
A salvação dos judeus: de São Paulo à declaração Nostra Aetate ${ }^{7}$
}

\author{
The salvation of the Jews: \\ from the apostle Paul to the Declaration Nostra Aetate
}

Jesus Hortal, S.J.

\section{Resumo}

Partindo da constatação das diferenças, desde os inícios, entre o cristianismo nascente e o judaísmo rabínico do século I, o autor levanta a questão de um possível antissemitismo nos escritos do Novo Testamento. Analisa a diversa posição dos Evangelho Sinóticos, de João e dos escritos paulinos, incluindo também o Livro dos Atos dos Apóstolos. O ponto centra da reflexão gira em torno às conclusões, ou melhor à perplexidade de Paulo na Epístola aos Romanos, sobre a salvação dos judeus. Mostra depois, como a Declaração Nostra Aetate do Concílio Vaticano II e o Catecismo da Igreja Católica continuam a mesma trilha paulina e conclui almejando a continuidade da reflexão teológica para procurar maior unidade entre as duas religiões abraâmicas, cristianismo e judaísmo.

Palavras-chave: Judeus. Novo Testamento. Antissemitismo. São Paulo. Salvação.

\section{Abstract}

Starting from the differences between Christianity and Judaism, verified since the first century, the author inquires over the existence of anti-Semitism

\footnotetext{
${ }^{1}$ Este artigo recolhe a contribuição do autor ao Seminário sobre o cinquentenário da Declaração Nostra Aetate, organizado, na PUC-Rio, pela Cátedra Carlo Maria Martini e pela Fraternidade Cristã-Judaica do Rio de Janeiro, em novembro de 2015.
} 
in the writings of the New Testament. He examines the diversified positions of the Synoptic Gospels and John; he throws also a glance on the Pauline writings, including Acts. The focus of the article lays on the perplexed mind of St. Paul about the salvation of the Jews. Afterwards, he shows haow the Declaration Nostra Aetate and the Catechism of the Catholic Church proceed in the same Pauline direction. At the end, the article advocate for further dialog between both Abrahamic religions, in order to tind a more profound understanding and unity.

Keywords: Jews. New Testament. Anti-Semitism. St. Paul.

\section{Introdução}

Não é fácil falar de um diálogo entre Igreja e Sinagoga, porque o que temos contemplado, ao longo dos séculos, foi fundamentalmente um relacionamento de incompreensões, hostilidades e fechamento mútuos. O Novo Testamento constitui, para os cristãos, não apenas uma fonte fundamental de história para as origens desse relacionamento, mas também um ponto de partida para a reflexão teológica. Vou limitar-me, neste pequeno trabalho, a expor alguns pontos surgidos da leitura assídua das Escrituras neotestamentárias. Depois tentarei mostrar a releitura feita pelo Concílio Vaticano II, na Declaração Nostra Aetate. É claro que esses pontos de vista deverão ser complementados com a visão surgida do Talmude e da tradição judaica, que não é tão conhecida como deveria sê-lo pelos cristãos e que precisaria de algum expositor judeu, versado nessa literatura e com abertura para o diálogo.

\section{Jesus, pedra de tropeço}

Desde os primórdios, o cristianismo apareceu como rival do judaísmo. Os Evangelhos apresentam a história de Jesus como o início de uma nova era. Ele é o novo Moisés, iniciador de uma nova Aliança. O simbolismo do número doze nos indica um novo Povo, com os doze Apóstolos, no lugar dos doze Patriarcas, tal como aparece na nova cidade santa, a nova Jerusalém dos capítulos 21 e 22 do livro do Apocalipse. Há também uma nova Lei - as Bem-aventuranças - promulgada igualmente sobre uma montanha sagrada, junto com uma releitura da Lei antiga, que não a nega, mas a "supera". Os Evangelistas, especialmente Mateus, insistem em apresentar Jesus como 
aquele que está acima da literalidade da Lei e de suas interpretações e que, por isso, pode falar "com autoridade". Não há apenas a proclamação da missão do Filho pelo Pai, no Batismo do Cristo, mas Moisés e Elias - a Lei e os Profetas - dão testemunho de Jesus na Transfiguração. O sacrifício da Cruz, antecipado na instituição da Eucaristia, é apontado como a nova Páscoa, consumadora de todos os sacrifícios antigos. Finalmente, o Pentecostes cristão - cinquenta dias após a morte de Jesus (Páscoa cristã), como o Pentecostes judeu foi cinquenta dias após a Páscoa libertadora do Egito - provoca também uma ação profética da primitiva comunidade cristã, que se lança à missão.

\section{Existe antissemitismo nos Evangelhos canônicos?}

Diante desses fatos, a primeira questão polêmica, insistentemente levantada pelos judeus, especialmente após a Segunda Guerra Mundial, é: existe antissemitismo no Novo Testamento? Sabemos que os nossos escritos sagrados são heterogêneos e redigidos ao longo de mais de setenta anos. $\mathrm{O}$ vocabulário e o estilo neles empregados variam notavelmente, de acordo com a época e os destinatários. Por isso, eles não podem ser interpretados sem levar em conta os leitores para os quais foram preparados.

Deixando, pois, inicialmente de lado os escritos paulinos, dos quais falaremos mais adiante, olhemos os Evangelhos. Mesmo admitindo a identificação de fragmentos da caverna 7 de Qumrã como pertencentes ao Evangelho de Marcos, é certo que ele é plenamente "cristão" e que foi redigido após a separação definitiva entre Igreja e Sinagoga, operada com a perseguição herodiana do ano 40 da nossa era. É o momento em que Tiago o Maior foi preso e executado, por volta do ano 42. Ao mesmo tempo, o grupo dos judeu-cristãos já tinha começado a regredir. Quase certamente, os outros três Evangelhos, pelo menos na versão que conservamos, são posteriores à catástrofe do ano 70, quando Jerusalém foi destruída e o povo de Israel disperso e quando os cristãos, seguindo o conselho de Jesus, fugiram "para as montanhas"2. Os evangelistas escreveram, pois, com a consciência de formarem uma comunidade à parte em face da sinagoga. Por isso, tentaram marcar as diferenças. Ao se difundir no seio do povo de Israel, era necessário, para a nova religião, acentuar a própria individualidade, contra a nostalgia do culto esplendoroso do templo e as formas de piedade tradicionais. É suficiente dar uma olhada na Carta

${ }^{2}$ Cf. Mt 24,16; Mc 13,14; Lc 21,21. 
aos Hebreus, para compreender essa concorrência acirrada e o modo como foi enfrentada pelos autores neotestamentários. O ponto fundamental da separação era e continuará a ser o caráter único de Jesus, algo inaceitável para o judaísmo. Contra toda a tradição rabínica, que reconhece uma pluralidade de mestres, o cristianismo apresentava um só, atribuindo-lhe ainda por cima natureza divina. Os cristãos, que no começo eram majoritariamente de origem judia, passaram a ser depois fundamentalmente gentios convertidos, inclusive um bom número de prosélitos, influenciados previamente pelo judaísmo. Nesse contexto, os evangelistas tentaram mostrar as causas que levaram Jesus à morte. Mas, escrevendo para leitores majoritariamente não hebreus, simplificaram as suas descrições, a fim de torná-las compreensíveis a todos e, talvez, de demonstrar que o conflito ideológico entre judaísmo e cristianismo era irreversível. Daí surgiram as denominações genéricas, que aparecem ao longo dos seus relatos: os adversários de Jesus são "os escribas e fariseus" (nos Sinóticos) ou "os judeus" (em João) 3; raramente, os "herodianos"; muito menos, os romanos. Apesar disso devemos reconhecer que a linguagem e muitas das ideias pregadas por Jesus se enquadram dentro da tradição rabínica; ainda mais, dentro da escola dos fariseus. Contudo, os que, na expressão dos evangelistas, se tornaram inimigos de Jesus parecem formar um grupo compacto e numeroso, que poderia ter sido constituído fundamentalmente pelos próprios fariseus. Advirtamos, porém, que os mesmos escritores, dentro da narrativa dos fatos que conduziram à morte de Jesus, fazem alusão também aos "sumos sacerdotes", ao "sinédrio", aos "príncipes [principais] dos sacerdotes", sem esquecer os "herodianos" e até "a multidão" e "o povo". Essa multiplicidade de denominações mostra claramente que os relatos não foram redigidos com a exatidão histórica que teríamos desejado. Curiosamente, os romanos, que, pelo menos, foram os responsáveis legais e os executores da pena capital contra Jesus, quase são esquecidos e desculpados. Até na tradição popular, o centurião que transpassou o costado de Jesus se transformou em "São Longinos" e não faltaram tentativas de atribuir também o caráter de santa à mulher de Pilatos, conhecida como Prócula. Dá a impressão de que

\footnotetext{
${ }^{3}$ Marcos, o mais primitivo dos evangelistas, usa seis vezes a expressão "os judeus"; Mateus e Lucas a empregam cinco vezes cada um. Mas destes três evangelistas, apenas Marcos a usa uma vez como referindo-se aos que poderiam ser qualificados de "inimigos" do cristianismo. João, ao contrário, o faz nada menos do que sessenta e cinco vezes. Lembremos que João escreveu certamente após a destruição de Jerusalém, quando a fratura entre cristianismo e judaísmo era irreversível e os seus leitores eram, na sua grande maioria, oriundos do paganismo e, desconhecedores, portanto, das diversas correntes judaicas de pensamento.
} 
o cristianismo nascente, ao mesmo tempo em que, tomando consciência de sua identidade, afirmava a própria personalidade em face do judaísmo, queria evitar, a todo custo, o conflito com o poder dominador. Por outro lado, para leitores de tradição não judaica, seria impossível explicar todas as divisões das escolas rabínicas. Daí o recurso a uma denominação genérica, que não podia ter, na sua origem um sentido antissemita, pois a quase totalidade dos autores do Novo Testamento foram judeus de raça, que não pretenderam renegar as suas origens. Pode ser iluminadora, a esse respeito, a distinção que é feita pelo documento Nós recordamos, do Pontifício Conselho para o Diálogo Religioso com o Judaísmo, entre "antijudaísmo" e "antissemitismo". O antijudaísmo brota da rivalidade religiosa; o antissemitismo, da étnica. Nos evangelistas aparecem claros traços de antijudaísmo; nenhum de antissemitismo. Não podemos, porém, negar que a transição do um para o outro não é difícil e que ela se deu, de fato, em numerosas ocasiões.

Uma comparação do Novo Testamento com os textos de Qumrã - escritos por uma comunidade de judeus piedosos, provavelmente de essênios, em conflito com os dirigentes do templo - mostra que o distanciamento e as condenações entre grupos rivais dentro do próprio judaísmo podiam assumir verbalmente uma generalização que dificilmente poderia ser entendida literalmente.

Examinando logicamente os textos dos Evangelhos, devemos dizer que nem a maioria do povo de Israel daquela época, nem sequer a maioria dos habitantes de Jerusalém tomaram parte ativa nos acontecimentos que levaram à morte de Jesus. Mesmo entre os "escribas e fariseus", parece ter existido uma pluralidade de opiniões maior do que à primeira vista possa parecer. A acusação de "deicídio" contra todos judeus, indiscriminadamente, não se pode fundamentar nos relatos evangélicos.

\section{A questão nos Atos dos Apóstolos e em São Paulo}

Embora inicialmente os Apóstolos continuassem a frequentar o Templo, não demorou muito tempo até que os cristãos fossem considerados hereges pelos sacerdotes. Perante a nova fé, proclamada na pregação apostólica, só cabiam duas atitudes: ou aceitá-la ou rejeitá-la e então combatê-la, como incompatível com a continuidade de Israel ${ }^{4}$. O livro dos Atos dos Apóstolos nos

\footnotetext{
${ }^{4}$ Essa incompatibilidade entre as duas fés, não obstante todas as coincidências, é manifestada de modo dramático por Neusner ( $A$ Rabbi talks with Jesus), citado por Ratzinger, na sua obra Jesus de Nazaré. A centralidade do próprio Jesus, que exigiu uma renúncia total, inclusive à
} 
narra as tentativas de supressão da nova "heresia", feitas pelas autoridades do Templo. De modo especial, destaca a perseguição do ano 40, que culmina com a morte de Tiago, por ordem de Herodes Antipas, fato que "agradou aos judeus" (At 12,3). Paulo, como ele próprio afirma repetidamente, tomou parte ativa na repressão ao cristianismo e posteriormente, após a sua conversão, teve que sofrer a mesma perseguição, o encarceramento e a morte. Coincidentemente, como no caso de Jesus, os acusadores de Paulo foram judeus, mas os executores da prisão e da pena de morte foram romanos. Uma expressão tardia dessa excomunhão aparece na "Oração das dezoito bênçãos" (Tefillah ou Amidah), de origem certamente pré-cristã, mas que, em algumas versões, inclui, na bênção de número doze, uma execração dos hereges (haminim) ${ }^{5}$ e, de modo especial, dos cristãos (nasri) e que ainda hoje é recitada em alguns círculos ortodoxos judaicos.

Como é lógico, as diferenças entre judeus e cristãos não se limitaram à Palestina. Os Atos dos Apóstolos e as cartas de São Paulo narram, sob a ótica do novel pregador, os choques ideológicos no amplo arco geográfico que se estende de Jerusalém até Roma e abarca a península da Ásia Menor, a Grécia e a Macedônia. Há, contudo, um fato que merece ser destacado. Naquele tempo, o judaísmo já não se limitava às fronteiras geográficas de Israel. Não só a diáspora, mas também a ação proselitista tinham dilatado fortemente o seu âmbito de expansão. O monoteísmo javista exercia uma forte atração entre as classes mais cultas do mundo greco-romano. Além dos prosélitos propriamente ditos, que se convertiam ao judaísmo e observavam os preceitos da Torá, havia um bom número de "tementes a Deus", os quais, sem aceitar todas as observâncias rituais, professavam a sua fé no Deus criador único, proclamado pelos judeus. Dos relatos paulinos se deduz claramente que tanto os judeus da diáspora, quanto os prosélitos e os tementes a Deus facilitaram a primeira expansão do cristianismo. Como é lógico, as conversões dessas pessoas ao cristianismo também contribuiu para um maior alheamento em relação ao judaísmo, que deve ter percebido nos cristãos rivais capazes de minar-lhe as bases.

O conflito se manifestou inicialmente até no seio do próprio cristianismo. Desenvolveu-se, de fato, uma Igreja judeu-cristã (Ecclesia ex circumcissione) e uma greco-cristã (Ecclesia ex gentibus). Além do episódio do chamado Concílio de Jerusalém, e das rixas em torno da distribuição das esmolas, re-

própria vida, para segui-lo, mostra claramente que Ele se colocou no lugar do próprio Deus, o que para o judaísmo tradicional foi a grande pedra de escândalo.

5 "Que os minim pereçam num instante, que sejam apagados do livro da vida". 
gistrados no livro dos Atos dos Apóstolos, o problema do judeu-cristianismo aparece bastante agudo na Carta aos Hebreus, onde o autor tem que polemizar contra uma nostalgia dos convertidos do judaísmo pelo esplendor do culto no Templo, frente à pobreza das reuniões cristãs. Não faltarão, por outro lado, nos primeiros séculos, grupos radicais que pretendam jogar fora tudo quanto possa lembrar o judaísmo, como a fixação da data da Páscoa, o uso do pão ázimo e até do vinho. É claramente um início do antijudaísmo, que infelizmente acompanhará a história da Igreja, ao longo dos séculos ${ }^{6}$.

No momento em que estoura a Primeira Guerra Judaica (67-70), os cristãos, na sua maioria, abandonaram Jerusalém e, seguindo a admonição de Jesus, "fugiram para as montanhas" (Mt 24,16), ou seja, de acordo com a tradição, para Pella, na Transjordânia. Por isso, podem ter dado a impressão de falta de patriotismo e traição à causa nacional, aprofundando a separação do cristianismo com o judaísmo majoritário. Talvez aí se encontre uma das razões do fim do judeu-cristianismo.

De 132 a 135, aconteceu a Segunda Guerra Judaica, liderada por Shimon ben Koseba, conhecido também como Shimon bar Kochbá (o "Filho da Estrela"), o qual fora reconhecido como Messias pelo mestre mais influente de sua época, o Rabi Akiba. Bar Kochbá, que no Talmude é considerado com um grande enganador do povo e por isso recebeu o nome de Bar Kosiba, ou Filho da Mentira; durante seu breve domínio, estabeleceu medidas persecutórias contra os cristãos, que não podiam aceitar suas pretensões messiânicas. Acabou morrendo em combate. Rabi Akiba, por sua parte, sofreu atroz martírio às mãos dos romanos, enquanto recitava o Shemá. Nunca mais, até a fundação do moderno Estado de Israel, foi restabelecida a soberania judia sobre a Palestina ${ }^{7}$. Ela ficará submetida primeiramente ao Império Romano; mais tarde ao Império Bizantino; com posterioridade, ao Império Árabe; cairá nas mãos

\footnotetext{
${ }^{6}$ Chamemos a atenção para a distinção entre antijudaísmo e antissemitismo. O primeiro tem raízes religiosas e vai normalmente unido a um forte desejo proselitista de conversão dos judeus. $\mathrm{O}$ antissemitismo, pelo contrário, tem uma base racista e rejeita os judeus, pelo simples fato de pertencerem a uma etnia. Por isso, dentro do antissemitismo, a conversão dos judeus carece de sentido; pelo contrário, conseguir essa conversão é a meta do antijudaísmo.

${ }^{7}$ Uma pequena observação sobre o nome Palestina. A denominação tradicional da Terra Santa, entre os judeus, foi sempre a de Eretz Yisrael, ou "Terra de Israel". Os romanos entraram em contato primeiramente com os "povos do mar" ou filisteus, aos quais chamavam de Pilistim, donde se derivou o nome de Palestina. Não se esqueça, por outro lado, que, no tempo da conquista romana, os asmoneus dominavam apenas a Judeia e, em parte, a Galileia. Daí que as moedas comemorativas da vitória de Vespasiano e Tito tenham uma figura feminina e a inscrição Iudaea capta e não Israel captus.
} 
dos turcos seljúcidas e otomanos, com o breve parêntese da dominação dos cruzados, e passará pelo domínio britânico, até 1948. Contudo, nunca deixará de haver alguma presença, mesmo mínima, de judeus na Terra Santa. A grande maioria dos israelitas, porém, viverá na diáspora, entre todos os povos. $\mathrm{Na}$ atualidade, os judeus que moram em Israel são algo mais de um terço da população judia mundial.

Em Paulo, o problema parece ser mais complexo do que nos Evangelhos. O zelo pelo judaísmo, que o impulsionou a tomar parte na repressão inicial contra o cristianismo nascente, acabou transformando-se em ardor proselitista pela nova religião, ao mesmo tempo em que sentia dentro de si o desgarramento interior, por causa de sua pertença ao povo de Israel. Nenhum outro escrito do Apóstolo exprime isso melhor do que a Carta aos Romanos, inquestionavelmente paulina. Junto com a Carta aos Gálatas, Romanos focaliza o problema principal da teologia paulina: a justificação pela fé. Mas, enquanto a Carta aos Gálatas foi escrita no ardor da polêmica intracristã, a Epístola aos Romanos é fruto de uma reflexão amadurecida sobre o mistério da salvação e o seu desenrolar na História. Eis um breve resumo dela:

O contexto é o de uma comunidade (a de Roma), onde, de acordo com as informações recebidas por Paulo, as divergências parecem conduzir a sérios desentendimentos entre os cristãos convertidos do judaísmo, de um lado, e os convertidos do paganismo, do outro. O escrito prepara uma visita do Apóstolo a essa comunidade, propondo uma solução para os problemas lá existentes, especificamente o da relação judaísmo-cristianismo. Na epístola, Paulo parte da contraposição entre Cristo, Justiça de Deus, e a justiça que os homens pretendem alcançar por seu próprio esforço, mediante as obras. Não nega o valor da antiga economia da salvação, mas lhe marca limites precisos. "A Lei é santa, justo e bom é o preceito" $(\mathrm{Rm} 7,12)$, anuncia claramente Paulo de Tarso; a Lei fez o homem conhecer a vontade divina. Ao mesmo tempo, ele se enfrenta com o problema da própria debilidade e a consciência da própria culpa e não consegue ver na Lei a ajuda necessária para superá-las. Daí a sua solução: somente em Cristo, encontra-se essa ajuda e ela se obtém através da fé. A consequência lógica seria a exclusão da salvação de todos os judeus que permanecessem no judaísmo.

Não é, pois, estranho que os escritos paulinos tenham sido considerados fonte da polêmica judeu-cristã e até acusados de serem antissemitas. Contudo, Paulo, na mesma Carta aos Romanos, não parece satisfeito com aquela 
dedução e passa a polemizar com os cristãos provenientes da gentilidade que, numa soberba mal dissimulada, desprezavam os judeus. Contra as conotações racistas que pareciam insinuar-se, ele deixa muito claro que, diante de Deus, não há acepção de pessoas. Todos os fiéis, seja qual for a sua origem, devem formar um só corpo (cf. Rm 12,1-15). Além disso - e este é o ponto mais importante -, Paulo está convencido de que aos israelitas "pertencem a adoção filial, a glória, as alianças, a legislação, o culto, as promessas, os patriarcas"; deles é "o Cristo segundo a carne" (Rm 9,4-5). Nos capítulos 10 e 11, a argumentação torna-se um tanto confusa, pois confusa parece estar a mente de Paulo, perante o mistério da salvação e os insondáveis desígnios de Deus. Por um lado, ele vê o que julga ser a incredulidade de Israel e lhe parece que, ao agirem os judeus desse modo, fica fechada para eles a porta da salvação. Por outro, porém, tem que reconhecer que "os dons e a vocação [eleição] de Deus são sem arrependimento [irrevogáveis]" (Rm 11,29). Daí conclui afirmando que "Deus encerrou todos na desobediência para a todos fazer misericórdia" (Rm 11, 32); por isso, entoa um hino à sabedoria misericordiosa do Senhor. Paulo focaliza certamente a dialética entre salvação individual e salvação comunitária do povo, sem conseguir chegar a uma conclusão completamente satisfatória.

A solução final cogitada por Paulo é uma solução que apela para o mistério e, ao mesmo tempo, apresenta uma certeza: "Não quero que ignoreis, irmãos, este mistério, para que não vos tenhais na conta de sábios: o endurecimento atingiu uma parte de Israel, até que chegue a plenitude dos gentios, e assim todo Israel será salvo, conforme está escrito:

\author{
De Sião virá o libertador \\ e afastará as impiedades de Jacó, \\ e esta será minha aliança com eles, \\ quando eu tirar seus pecados (Rm 11,25-27).
}

Diante dessas afirmações, é lícito perguntar-nos se, para Paulo, dada a irrevogabilidade da promessa divina, o judaísmo continua a ser caminho de salvação - imperfeito, sim, mas verdadeiro - para o povo de Israel, à espera de que "todo Israel" seja salvo. E, se Paulo pensava assim, podemos nós pensar de modo diferente? Até que ponto, então, é legítimo o proselitismo cristão entre os judeus? 


\section{A polêmica antijudia ao longo da história}

A Igreja, porém, não aprofundou essa reflexão paulina. Em grande parte, devido ao fato de que, no âmbito cultural greco-romano, religião e política caminharam estreitamente unidas. Qualquer dissidência da confissão majoritária era concebida como uma traição ao Estado. Tanto o césaro-papismo oriental quanto o feudalismo ocidental deram lugar a concepções que viam na unidade de fé, não só um ideal a ser atingido, mas também uma necessidade vital para a sobrevivência do Estado. Mesmo em plena época moderna, a Guerra dos Trinta Anos terminou com o reconhecimento explícito do axioma cuius regio, eius et religio ("de quem é a região, é também a religião"). Na realidade, era esse um princípio que se encontrava em vigor já fazia séculos. Os tribunais da Inquisição, sobretudo da espanhola e portuguesa foram, por isso, mais tribunais políticos do que religiosos.

A separação entre Igreja e Estado, no Ocidente, foi um processo lento e custoso, que se inicia com a Revolução francesa e somente se completa após a Segunda Guerra Mundial.

Não é, pois estranho, que a situação dos judeus nos países cristãos tenha sofrido de terríveis incompreensões, calúnias e perseguições. Conhecemos como essa evolução histórica desembocou na terrível tragédia do Holocausto.

\section{O Concílio Vaticano II - Declaração Nostra Aetate}

Quando João XXIII convocou o Concílio Vaticano II, a situação da Europa tinha mudado radicalmente. Ninguém pensou em qualquer documento sobre o judaísmo. Afinal, o Concílio era um acontecimento interno da Igreja católica. No máximo, a atenção se voltava para o movimento ecumênico, dado que, em 1948 surgira o Conselho Mundial de Igrejas. Mas alguém que sofrera na própria carne os horrores da perseguição nazista teve a intuição de ver no Concilio uma oportunidade única de reconciliação. Foi o prof. Jules Isaac, historiador e intelectual francês que, tendo conseguido uma Audiência particular como Papa Roncalli, solicitou que o Concílio emitisse uma declaração sobre os judeus. João XXIII acolheu a proposta com simpatia e pediu ao Cardeal Agostinho Bea, um cardeal alemão e jesuíta que elaborasse uma proposta. Não foi nada fácil encontrar o lugar apropriado. No fim, decidiu-se que, em lugar de uma declaração particular sobre o judaísmo, a assembleia conciliar emitisse um documento sobre a Igreja Católica e as Religiões não cristãs. Tra- 
ta-se da Declaração Nostra Aetate ("No nosso tempo") cujo cinquentenário estamos celebrando. Foi aprovada na aula conciliar no dia 28 de outubro de 1965.

É uma declaração breve, estruturada em cinco pontos. Partindo da constatação do anseio religioso da humanidade (n. 1), examina, em particular algumas religiões mais difundidas: hinduísmo e budismo (n. 2), islamismo (n. 3) e, de modo mais pormenorizado, a religião judaica (n. 4). Ao falar dela, chama a atenção para o rico patrimônio comum de judeus e cristãos, invoca depois o testemunho de São Paulo, na mesma linha que já expusemos, rejeita as acusações que se encontram na base do antissemitismo e, a partir daí, condena toda discriminação contra os judeus. A declaração se encerra, no n. 5, com uma apelo à concórdia e à paz universal.

\section{O catecismo da Igreja Católica}

O moderno Catecismo da Igreja Católica recolhe esses ensinamentos e lhes dá uma nova expressão. Nos nn. 59-67, num rápido olhar panorâmico, mostra o papel do Povo de Israel no que conhecemos como História da Salvação. Transcrevemos os nn. 68-73, onde se contém um resumo desses ensinamentos:

68 Por amor, Deus revelou-se e doou-se ao homem. Traz assim uma resposta definitiva e superabundante às questões que o homem se faz acerca do sentido e do objetivo da sua vida.

69 Deus revelou-se ao homem comunicando-lhe gratuitamente o seu próprio Mistério através de ações e palavras.

70 Para além do testemunho que Deus dá de si mesmo nas coisas criadas, ele manifestou-se pessoalmente aos nosso primeiros pais. Falou-lhes e, depois da queda, prometeu-lhes a salvação e ofereceu-lhes a sua aliança.

71 Deus fez com Noé uma aliança eterna entre ele e todos os seres vivos. Esta há de durar enquanto durar o mundo.

72 Deus escolheu Abraão e fez uma aliança com ele e sua descendência. Daí formou seu povo, ao qual revelou a sua lei através de Moisés. Pelos profetas preparou este povo a acolher a salvação destinada à humanidade inteira.

73 Deus revelou-se plenamente enviando seu próprio Filho, no qual estabeleceu a sua Aliança para sempre. O Filho é a Palavra definitiva do Pai, de sorte que depois dele não haverá mais outra revelação. 
É evidente, a partir desses textos, que a História da Igreja resulta incompreensível sem a História de Israel. Mas também é claro que uma compreensão parcial e estreita deles pode provocar, como de fato provocou ao longo dos séculos, atitudes proselitistas e até antijudias. O caso mais típico e de consequências mais negativas ao longo da história talvez seja o do julgamento e morte de Jesus. Uma vez mais, permito-me citar o Catecismo da Igreja Católica, para deixar clara a nossa posição atual:

597 Levando em conta a complexidade histórica do processo de Jesus, manifestada nos relatos evangélicos, e qualquer que possa ser o pecado pessoal dos atores do processo (Judas, o sinédrio, Pilatos), conhecido só de Deus, não se pode atribuir a responsabilidade ao conjunto dos judeus de Jerusalém, a despeito dos gritos de uma multidão manipulada e das censuras globais contidas nos apelos à conversão depois de Pentecostes. O próprio Jesus, ao perdoar na cruz, e Pedro depois dele, apelaram para a "ignorância" (At 3,17) dos judeus de Jerusalém e até dos chefes deles. Menos ainda pode-se, a partir do grito do povo: "O seu sangue caia sobre nós e sobre os nossos filhos", que significa uma fórmula de ratificação, estender a responsabilidade aos outros judeus no espaço e no tempo".

\section{Conclusão}

As limitações de espaço não nos permitem comentar outros documentos, onde se traçam linhas para o ensinamento cristão sobre o judaísmo. Baste citar, para quem deseje aprofundar o tema, dois deles: As "Notas para a Correta Apresentação dos Judeus e do Judaísmo, na Pregação e na Catequese da Igreja Católica Romana”, publicadas pela Pontifícia Comissão para o Diálogo religioso com o Judaísmo, em 1985, e as "Recomendações sobre a Educação nos Seminários Católicos e Judeus e nas escolas de Teologia”, aprovadas pela mesma Comissão na reunião de maio de 2001, em Nova York.

Creio que o caminho está aberto, mas que é preciso continuar a percorrê -lo. Temos belíssimos documentos. Contudo, uma grande maioria dos católicos nem sequer toma conhecimento deles e continua a trilhar veredas antigas, que não conduzem a parte nenhuma. O esforço deve ser de todos, porque todos estamos umbilicalmente unidos na fé do Deus de Abraão, que nos conduz pelos caminhos da história. 


\section{Referências bibliográficas}

BÍBLIA DE JERUSALÉN. 4 ${ }^{a}$ edição. España: Desclée De Brouwer, 2009.

CONCÍLIO VATICANO II. Declaração Nostra Aetate - sobre a Igreja e as religiões não cristãs. Disponível em: http://www.vatican.va/archive/ hist_councils/ii_vatican_council/documents/vat-ii_decl_19651028_nostra-aetate_po.html. Acesso em 10 de novembro de 2015.

RATZINGER, J. Jesus de Nazaré: primeira parte - do Batismo no Jordão à Transfiguração. São Paulo: Editora Planeta do Brasil, 2007.

Jesus Hortal, S.J. Doutor em Direito Canônico pela Pontificia Università Gregoriana (Roma) Professor emérito da Pontifícia Universidade Católica do Rio de Janeiro Rio de Janeiro / RJ - Brasil E-mail: hortal@puc-rio.br

Recebido em: 05/03/16 Aprovado em: 12/04/16 